\title{
Movement of Dichlorvos in Farm Soils: Batch and Column Studies.
}

\section{Nahuel Bustos}

CONICET: Consejo Nacional de Investigaciones Cientificas y Tecnicas

\section{Diego Grassi}

University of Buenos Aires: Universidad de Buenos Aires

\section{Alicia Fernández Cirelli}

CONICET: Consejo Nacional de Investigaciones Cientificas y Tecnicas

Analia Iriel ( $\nabla$ iriel.analia@gmail.com )

CONICET: Consejo Nacional de Investigaciones Cientificas y Tecnicas https://orcid.org/0000-00015763-3712

\section{Research}

Keywords: agricultural soils, insecticide mobility, adsorption, desorption, non-equilibrium sorption

Posted Date: December 28th, 2020

DOl: https://doi.org/10.21203/rs.3.rs-133555/v1

License: (1) (1) This work is licensed under a Creative Commons Attribution 4.0 International License. Read Full License 
Movement of dichlorvos in farm soils: batch and column studies.

Nahuel J. Bustos, ${ }^{1}$ Diego Grassi, ${ }^{2}$ Alicia Fernández Cirelli ${ }^{1,2}$ and Analia Iriel ${ }^{1,2 *}$

${ }^{1}$ CONICET - Universidad de Buenos Aires. Instituto de Investigaciones en Producción Animal (INPA). Buenos Aires. Argentina. ${ }^{2}$ Universidad de Buenos Aires, Facultad de Ciencias Veterinarias, Centro de Estudios Transdisciplinarios del Agua (CETA). Buenos Aires, Argentina.

*Corresponding author: iriel.analia@gmail.com

\section{Abstract}

Soils are the principal environmental fate of pesticides in agricultural areas. Thus, the kinetics, extension, and strength of the adsorption process become critical. Dichlorvos (DDVP) is an organophosphorous pesticide that is used both in agriculture and livestock production. Sorption/desorption assays of DDVP in two agricultural soils (with different textural characteristics) from Pampa Plain (Argentina) were performed in both batch and column systems. From batch studies, kinetics and sorption/desorption equilibrium parameters were estimated. Our results showed that the maxima adsorption is reached after $30 \mathrm{~h}$ of time of contact and followed a pseudo-first-order rate. Adsorption/desorption data were well fitted to the Freundlich model obtaining high adsorption constants of 90 $\mu \mathrm{g}^{(1-1 / \mathrm{n})} \mathrm{mL}^{(1 / \mathrm{n})} \mathrm{g}^{-1}$ and $21 \mu \mathrm{g}^{(1-1 / \mathrm{n})} \mathrm{mL}^{(1 / \mathrm{n})} \mathrm{g}^{-1}$ for the clay loam and sandy loam soil, respectively. The isotherms were non-linear in both cases and the desorption process was unfavourable. Also, positive hysteresis was present for the sandy loam soil. From column studies, breakthrough curves were used to evaluate the mobility of DDVP in the soils at 1,10 , and $50 \mathrm{mg} \mathrm{L}^{-1}$ of DDVP. Eluted profiles were asymmetrical as well they presented 
retardation effects that were in connection with the results in batch conditions. Nonequilibrium sorption was stated for the DDVP movement through columns. Thus, high mobility was observed for DDVP in both soils despite their textural differences.

Keywords: agricultural soils; insecticide mobility; adsorption; desorption, nonequilibrium sorption

\section{Introduction}

In the last decades, agricultural countries have undergone an important expansion in their activities due to the development of new technologies and an increase in the specialization to attain worldwide food demands. Therefore, there was an increase in the use of phytosanitary products (mainly herbicides, insecticides, and fungicides) to improve crop production yield. However, the excessive application of pesticides has become an important environmental issue due to the high environmental concentrations found and the deleterious effects on non-target individuals $[1,2,3,4]$. Organophosphate pesticides are used in both agriculture and animal production being dichlorvos (2,2-dichlorovinyl dimethyl phosphate, DDVP) one of the most employed of this family. DDVP is an acetylcholinesterase inhibitor that is effective against mushroom flies, aphids, spider mites, caterpillars, and whiteflies in the greenhouse, outdoor fruit, and vegetable crops. Moreover, it is used to treat a variety of parasitic worm infections in livestock, dogs, and humans [1]. Exposure to DDVP in living organisms can lead to several affections related to neurological, reproductive, immunological, hepatic, renal, respiratory, and metabolic systems $[3,5]$. In cultivated regions, soils and streams play an important role in the transport and fate of pesticides used in crops and farms. There, pesticides can undergo several processes such as adsorption, leaching, run-off, volatilization, and degradation 
51 (biotic or abiotic) affecting the environmental concentrations $[6,7,8]$. DDVP has a short

52 half-lifetime in freshwater $\left(2.8\right.$ days at $\mathrm{pH}=7$ and $\left.20^{\circ} \mathrm{C}\right)$ [9] and soils (4 days at $\mathrm{pH}=6.2$ -

7.4 and $25^{\circ} \mathrm{C}$ ) [10]. However, dissolved organic matter in freshwater could affect the DDVP behaviour reducing both, its photodegradation rate [8] and its biodisponibility [11]. Moreover, groundwater contamination is not expected, according to its low Gustafson index of 0.69 [12]. According to European regulations, the maximum limit for

57 priority substances in the inland waters is $0.0006 \mu \mathrm{g} \mathrm{L}^{-1}$ according to water policy [13]. However, DDVP was detected ranging from 0.05 to $7.50 \mu \mathrm{gL}^{-1}$ in freshwater $[14,15]$. In Argentina, DDVP was the most detected insecticide in fish species collected from farm areas located at the Pampa Plain [16].

Adsorption studies are crucial to predict environmental fate constituting a valuable tool to perform risk assessment evaluations [17]. Sorption studies of pesticides in soils were extensively reported in the literature, however, among the insecticides, DDVP adsorption studies are scarce [18]. Furthermore, there are no studies on the interaction of dichlorvos with Argentinean soils. This study describes the adsorption behaviour of DDVP from batch and column experiments carried out on two soils with different textural properties and destined for agricultural and livestock activities.

\section{Materials and Methods}

\subsection{Chemicals}

All reagents were analytical grade, and they were used without further purification. Dichlorvos was purchased from Sigma-Aldrich Pestanal (Germany); phosphoric acid, Anedra (Argentina); sodium azide, Biopack (Argentina), and calcium chloride, Merck 
HPLC - grade. Solutions were prepared using deionized water obtained from a milli-Q purification system and kept at $4^{\circ} \mathrm{C}$.

\subsection{Soils}

Three soil samples were taken from two farms within Buenos Aires province (Argentina), referred to as:

$$
\text { 9S - } 9 \text { de Julio: } 35^{\circ} 21^{\prime} 19^{\prime \prime} \mathrm{S} \text { and } 60^{\circ} 41^{\prime} 48^{\prime \prime} \mathrm{W}
$$

MS - Mercedes: $34^{\circ} 40^{\prime} 29^{\prime \prime} \mathrm{S}$ and $59^{\circ} 25^{\prime} 14^{\prime \prime} \mathrm{W}$

Soil samples were collected from a depth of $5-20 \mathrm{~cm}$ of soil. They were air-dried, passed through a $2 \mathrm{~mm}$ sieve, and stored in plastic bags at room temperature until use. Soils were characterized according to standard procedures [19]: potentiometric method ( $\mathrm{pH}$ and Electrical Conductivity), Walkley-Black method (organic matter content), ammonium acetate distillation (cation exchange capacity, C.E.C.), and hydrometric (texture).

\subsection{Batch experiments}

Batch adsorption/desorption experiments were performed at room temperature by triplicate according to the OECD Technical Guideline 106 [20]. To determine the adsorption and desorption parameters a ratio of $6 \mathrm{~g}$ of soil per $100 \mathrm{~mL}$ of solution was set from preliminary experiments (data not shown). Thus, soils were pre-equilibrated with $\mathrm{CaCl}_{2} 0.01 \mathrm{M}$ and $\mathrm{NaN}_{3} 0.1 \mathrm{M}$ solutions during $12 \mathrm{~h}$. After that, dispersions were added with the necessary volume of a DDVP solution until a final concentration of $5 \mu \mathrm{g} \mathrm{mL} \mathrm{m}^{-1}$. A volume of $500 \mathrm{~mL}$ was kept under agitation for $30 \mathrm{~h}$ on shade conditions to avoid dichlorvos photodegradation. During this time, dispersion samples of $5 \mathrm{~mL}$ were 
periodically collected to investigate the variation of DDVP concentration in the

101

102

103

104

105

106

107

108

109

110

111

112

113

114

115

116

117

118

119

120

121

122

123

124

supernatant. Collected samples were centrifuged and soil particles were removed using a nylon filter $(0.45 \mu \mathrm{m})$ coupled to a syringe where any adsorption was detected. DDVP was quantified by HPLC as was described below (see Section 2.5). From these results, the equilibrium time was stated as the time at which DDVP concentration remains constant in the solution. Adsorption/desorption isotherms were constructed varying the starting DDVP concentration ranging from 5 to $500 \mu \mathrm{g} \mathrm{mL} \mathrm{m}^{-1}$. A mass of $0.6 \mathrm{~g}$ of each soil (previously equilibrated with $\mathrm{CaCl}_{2}$ and $\mathrm{NaN}_{3}$ solutions) was in contact with $10 \mathrm{~mL}$ of DDVP solution and the dispersions were stirred for $30 \mathrm{hs}$. The concentration of DDVP adsorbed is calculated as:

$$
\mathrm{q}_{\mathrm{e}}^{\text {ads }}=\frac{\left(\mathrm{C}_{0}-\mathrm{C}_{\mathrm{e}}\right) \mathrm{V}}{\mathrm{m}}
$$

where $\mathrm{C}_{0}$ and $\mathrm{C}_{\mathrm{e}}$ are both the DDVP concentrations in the solution at initial and at equilibrium time, respectively, expressed as $\mu \mathrm{g} \mathrm{mL}{ }^{-1}, \mathrm{~V}$ is the solution volume $(\mathrm{mL})$ and $\mathrm{m}$ is the soil mass $(\mathrm{g})$.

Desorption assays were conducted with the remaining solid of the adsorption studies described before. Soils were re-suspended in $10 \mathrm{~mL}$ of $\mathrm{CaCl}_{2}$ and the new dispersions were shaken for 30 hours. Finally, the amount of DDVP desorbed was calculated as:

$$
q_{e}^{d e s}=q_{e}^{a d s}-\frac{C_{e} V}{m}
$$

where $q_{e}^{a d s}$ was previously calculated by Eq. $1, C_{e}$ is the DDVP concentration obtained in the desorption experiment (expressed as $\mu \mathrm{g} \mathrm{mL}^{-1}$ ), $m$ is the mass of the remaining soil (g) and $V$ is the solution volume $(10 \mathrm{~mL})$. 


\subsection{Column movement experiments}

127 Continuous flow experiments were performed in a borosilicate column (3.5 cm long; 4.9 $\mathrm{cm}^{2}$ cross-sectional area) where air-dried soils were packed. Soils were initially saturated with a $\mathrm{CaCl}_{2}$ 0.01 M solution. DDVP solutions at several concentrations $(1,5$, and $50 \mu \mathrm{g}$

$\mathrm{L}^{-1}$ ) were pumped from the top with a mean flow rate of $1 \mathrm{~cm}^{3} \mathrm{~min}^{-1}$ by using a peristaltic pump. Then, the applied pesticide was displaced through the column with a solution of

$\mathrm{CaCl}_{2}$. Samples were collected from the end of the column at different time intervals until the exit concentration equals the inlet. Studies were performed by duplicate at room temperature $\left(22 \pm 1{ }^{\circ} \mathrm{C}\right)$. The column pore volume was calculated as:

$V_{p}=\frac{V}{V_{0}}$

where $\mathrm{V}$ is cumulative outflow volume and $\mathrm{V}_{0}$ is the total water volume into the column.

This was obtained gravimetrically at the end of each displacement.

Under operating conditions, the volume samples (obtained at different times) were used to construct the breakthrough curve (BTC) where the dichlorvos concentration was expressed as a relative concentration, $\mathrm{C} / \mathrm{C}_{0}$.

\subsection{Data analysis}

The rate, strength, and extent of dichlorvos adsorption on soils were evaluated by using kinetics and equilibrium models to obtain the physicochemical parameters involved in the adsorption process. 
151 The pseudo-order and the rate adsorption were assessed fitting the experimental data to

152 the kinetics models based on the adsorbent capacity such as the Lagergren equation [21]

153 and the Ho expression [22]. The pseudo-first-order (PFO) model assumes that the rate

154 adsorption is proportional to the driving force representing by:

155

$156 \frac{d q_{t}}{d t}=k_{1}\left(q_{e}-q_{t}\right)$

157

158 where $k_{l}$ is the PFO rate constant $\left(\mathrm{h}^{-1}\right), q_{e}\left(\mu \mathrm{g} \mathrm{g}^{-1}\right)$ is the adsorbed concentration of DDVP

159 in the soil particles at the equilibrium time and $q_{t}\left(\mu \mathrm{g} \mathrm{g}^{-1}\right)$ is the concentration of DDVP

160 adsorbed at soil particles at the evaluated time, t. The integrated expression is:

161

162

$q_{t}=q_{e}\left(1-e^{-k_{1} t}\right)$

163

164 The pseudo-second-order (PSO) model assumes that the adsorption rate is proportional 165 to the square of the driving force [22]:

166

$167 \quad \frac{d q_{t}}{d t}=k_{2}\left(q_{e}-q_{t}\right)^{2}$

168

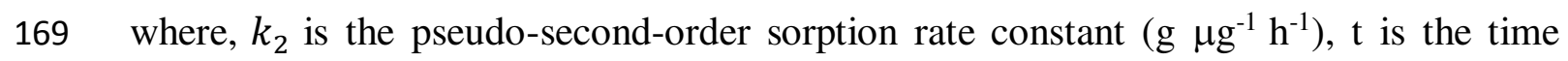
170 expressed in hours and $q_{e}$ and $q_{t}$ were previously defined in the text. Its integrated 171 expression can be written as:

172

$173 \quad q_{t}=\frac{q_{e}^{2} k_{2} t}{1+q_{e} k_{2} t}$ 


\subsubsection{Equilibrium assays}

176 From equilibrium experiments, adsorption/desorption isotherms of DDVP were evaluated relating to the quantity of DDVP adsorbed and remained in the solution at the equilibrium time. Moreover, Langmuir and Freundlich's models were used to estimate the adsorption parameters related. Langmuir model assumes that the adsorption takes place forming a monolayer of the solute molecules on the solid particles:

181

182

$q_{e}=\frac{\mathrm{Q}_{0} K_{L} C_{e}}{1+K_{L} C_{e}}$

where $\mathrm{Q}_{0}$ (expressed as $\mu \mathrm{g} \mathrm{g}^{-1}$ ) represents the maxima coverage capacity and the

Langmuir constant, $\mathrm{K}_{\mathrm{L}}$, is related to the affinity between the DDVP molecules and the adsorbent soil particles.

Data were also fitted to the Freundlich equation to estimate the equilibrium constant of both adsorption and desorption processes as is suggested by the OECD normative [20]. For that, the exponential equation was used:

where $K_{F}$ and $1 / n$ representing the adsorption capacity (adsorption constant) and the adsorption intensity, respectively.

197 The quantity of DDPV desorbed was calculated using the Eq. 9 where $q_{e}^{\text {des }}$ is the DDVP 198 adsorbed after a cycle of desorption, $q_{e}^{a d s}$ is the quantity of DDVP initially adsorbed, 
$199 C_{a q}^{d e s}$ is the concentration of DDVP in the desorption solution, $V_{0}$ is the volume of $\mathrm{CaCl}_{2}$ 200 solution $(\mathrm{mL})$ and $m_{\text {soil }}$ is the soil mass $(\mathrm{g})$.

201

202

$$
q_{e}^{d e s}=q_{e}^{a d s}-\left(C_{a q}^{d e s} x \frac{V_{0}}{m_{\text {soil }}}\right)
$$

203

Additionally, the hysteresis coefficient $(\mathrm{H})$ was calculated according to Eq. 10 [23]:

205

$206 \quad H=\frac{\left(\frac{1}{n} \text { desorption }\right)}{\left(\frac{1}{n} \text { adsorption }\right)}$

207

208

where $1 / n$ was previously estimated from the desorption and adsorption isotherms. An $\mathrm{H}$

$<1$ value (positive hysteresis) means that DDVP molecules tend to be adsorbed whereas, an $\mathrm{H}>1$ value (negative hysteresis) suggests that the desorption process is favoured. Additionally, if $\mathrm{H}=1$ the hysteresis is considered to be absent and the process is considered reversible [23].

213

\subsection{Dichlorvos measurements}

215

DDVP was determined through a high-performance liquid-chromatography (HPLC) system (Shimadzu LC-20A) equipped with a UV-Vis detector. The mobile phase consisted of a $65: 35$ volumetric mixture of $1 \mathrm{mM}$ phosphoric acid and acetonitrile. The used column was a Shimadzu Shim-pack VP-ODS: $25 \mathrm{~cm}$ x $4.6 \mathrm{~mm}$, particle size $5 \mu \mathrm{m}$ which was preconditioned at $22{ }^{\circ} \mathrm{C}$. The flow rate was set at $1.2 \mathrm{~mL} \mathrm{~min}{ }^{-1}$ and the detection was performed at $205 \mathrm{~nm}$. All samples were previously filtered using $0.22 \mu \mathrm{m}$ nylon filters. Determined LOD and LOC were $0.025 \mu \mathrm{g} \mathrm{mL}-1$ and $0.076 \mu \mathrm{g} \mathrm{mL}^{-1}$, respectively. 
225 Graphics and data analysis were done by using Sigma Plot 11.0 [24].

\section{Results and discussion}

\subsection{Soil properties}

229 The physicochemical and textural properties of collected soils are shown in Table 1.

230 Table 1. Properties of soils used in this study.

\begin{tabular}{|c|c|c|}
\hline Properties & \multicolumn{2}{|c|}{ Soils } \\
\hline & MS & 9 S \\
\hline $\mathrm{pH}\left(\mathrm{H}_{2} \mathrm{O}\right)$ & 6.95 & 6.46 \\
\hline E.C. $\left(\mathrm{dS} \mathrm{m}^{-1}\right)$ & 0.17 & 0.11 \\
\hline C.E.C. $\left(\mathrm{cmolc} \mathrm{kg}^{-1}\right)$ & 18.56 & 10.38 \\
\hline O.C. $(\% \mathrm{w}, \mathrm{w})$ & 1.81 & 0.67 \\
\hline$\%$ Clay & 35 & 12.5 \\
\hline$\%$ Silt & 42.5 & 2.5 \\
\hline \% Sand & 22.5 & 85.0 \\
\hline Textural Classification & clay loam & sandy loam \\
\hline
\end{tabular}

231

232 Samples were taken from locations where dairy farms are installed but without animal occupation. Studied soils have presented different textural properties being SM clayed loam while 9S soil had a higher sand content (85\%). Regarding $\mathrm{pH}$ values, they were similar although MS was slightly more alkaline. As well, the organic carbon content resulted in around 2.5 times lower for 9S $(0.67 \%)$. 


\subsection{Kinetics studies}

239 Adsorption rate parameters and the equilibrium time were estimated from the analysis of DDVP concentration and the time of contact with MS and 9S soils (Figure 1).

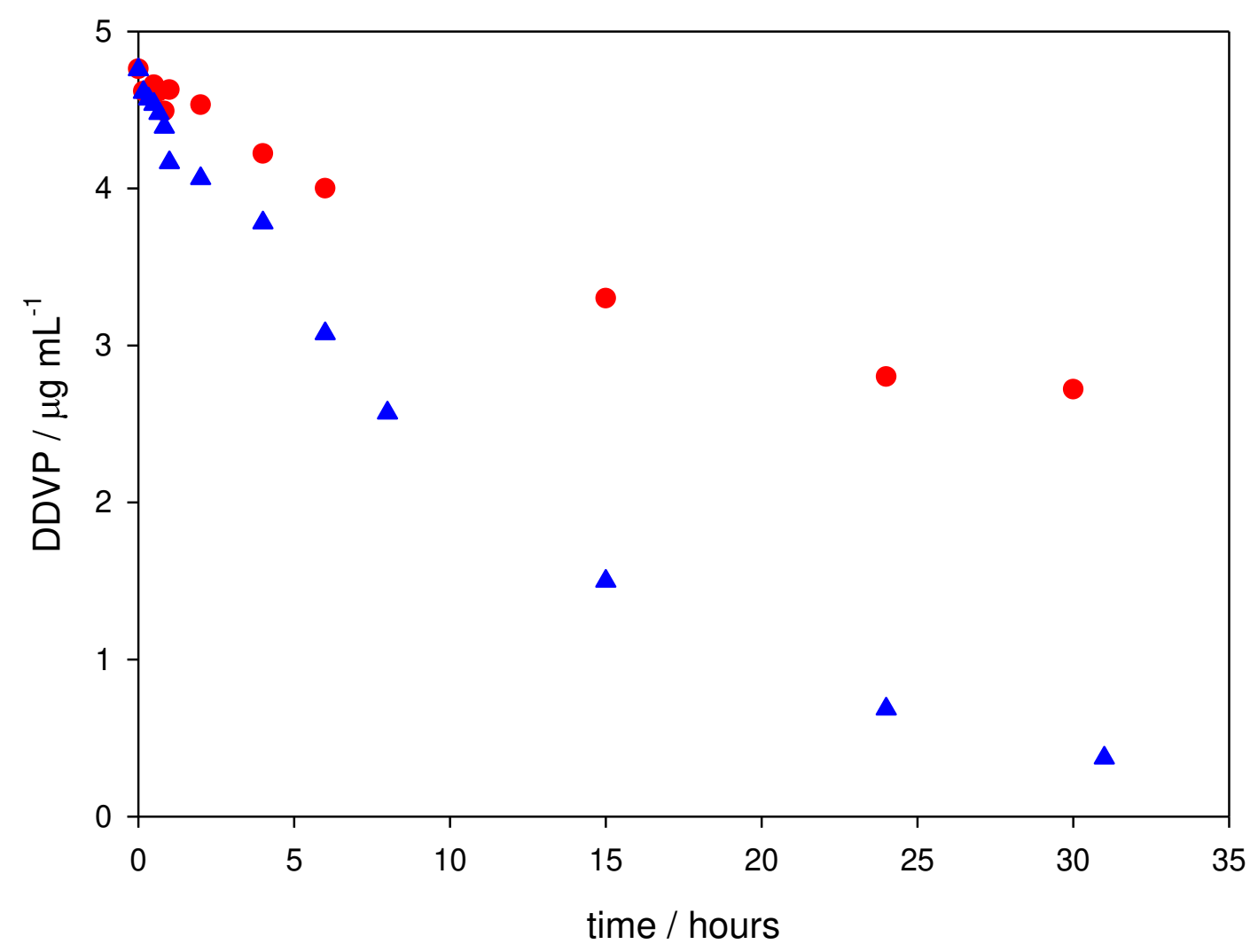

242 Figure 1. DDVP concentration as a function of contact time MS $(\boldsymbol{\Delta})$ and $9 \mathrm{~S}(\bullet)$ soils.

243 Initial DDVP concentration: $5 \mu \mathrm{g} \mathrm{mL}^{-1}$, soil dosage: $6 \mathrm{~g} \mathrm{~L}^{-1}$.

244

245 The adsorption of DDVP on soil particles took place within 30 hours reaching maxima 246 values of $92 \%$ and $43 \%$ for MS and 9S, respectively, from a starting concentration of 5 $247 \mu \mathrm{g} \mathrm{mL}^{-1}$ of DDPV. Differences between the adsorption in both soils could be related to 248 the low value of O.C. content and clay (\%) in 9S regarding MS [25]. Besides, 249 experimental data were adjusted to PFO and PSO models (see Figure 2) and kinetics 250 parameters were obtained (see Table 2). 


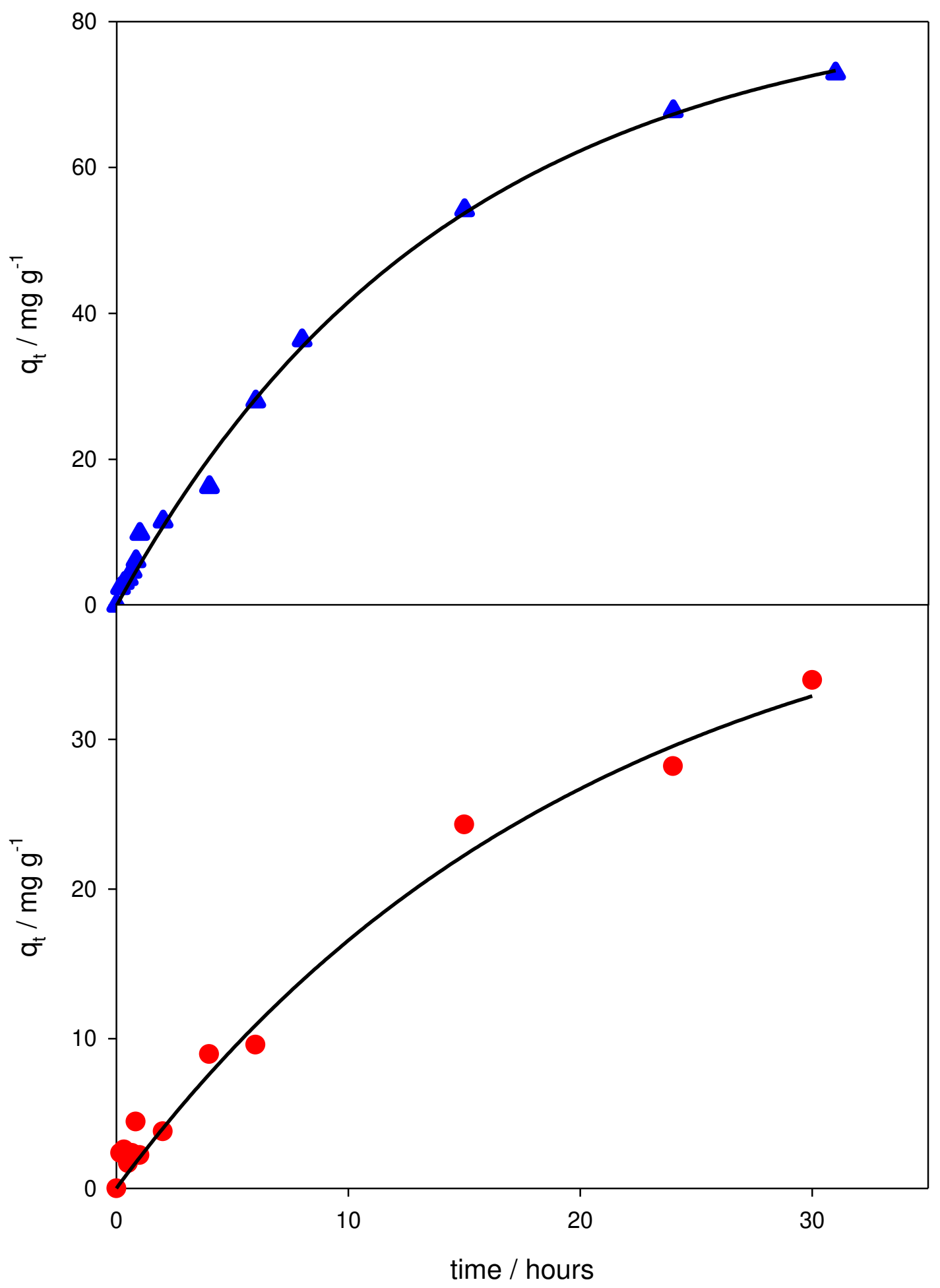

252 Figure 2. Fitting of experimental data of DDPV adsorption on soils MS ( $\boldsymbol{\Delta})$ and 9S (•) 253 to the PFO model (full line). 
From Table 2, it is observed that experimental data adjusted very well to both proposed models being the correlation coefficients very close between them. However, the analysis of the others parameters indicated that DDVP adsorption had a better agreement with the PFO as is denoted by the coincidence between the experimental and theoretical adsorption capacities values for the two soils indicating that the DDVP adsorption processes followed a PFO law where the film diffusion is the rate-controlling of the processes.

Otherwise, the parameters obtained from the fitting by PSO model were unacceptable (overestimates the adsorption capacity) suggesting that the rate-limiting step appeared not to be controlled by a chemical process [26].

Table 2. Kinetic parameters and $q_{e}$ experimental values for the adsorption of dichlorvos onto farm soils.

\begin{tabular}{|c|c|c|}
\hline & MS & $9 \mathrm{~S}$ \\
\hline & $\mathrm{q}_{\mathrm{e}(\exp )}=72.95 \mu \mathrm{g} \mathrm{g}^{-1}$ & $\mathrm{q}_{\mathrm{e}(\exp )}=33.55 \mu \mathrm{g} \mathrm{g}^{-1}$ \\
\hline \multirow{3}{*}{ PFO } & $\mathrm{k}_{1}=0.070 \pm 0.005 \mathrm{~h}^{-1}$ & $\mathrm{k}_{1}=0.06 \pm 0.01 \mathrm{~h}^{-1}$ \\
\hline & $\mathrm{q}_{\mathrm{e}(\text { theo })}=82 \pm 3 \mu \mathrm{g} \mathrm{g}^{-1}$ & $\mathrm{q}_{\mathrm{e}(\text { theo })}=42 \pm 5 \mu \mathrm{g} \mathrm{g}^{-1}$ \\
\hline & $\mathrm{R}^{2}=0.995$ & $\mathrm{R}^{2}=0.983$ \\
\hline \multirow{3}{*}{ PSO } & $\mathrm{k}_{2}=0.43 \pm 0.01 \mathrm{~g} \mathrm{mg}^{-1} \mathrm{~h}^{-1}$ & $\mathrm{k}_{2}=0.64 \pm 0.02 \mathrm{~g} \mathrm{mg}^{-1} \mathrm{~h}^{-1}$ \\
\hline & $\mathrm{q}_{\mathrm{e}(\text { theo })}=120 \pm 3 \mu \mathrm{g} \mathrm{g}^{-1}$ & $\mathrm{q}_{\mathrm{e}(\mathrm{theo})}=65 \pm 4 \mu \mathrm{g} \mathrm{g}^{-1}$ \\
\hline & $\mathrm{R}^{2}=0.994$ & $\mathrm{R}^{2}=0.984$ \\
\hline
\end{tabular}

Although DDVP has been studied for a long time, no adsorption assays have been carried out on productive soils having a lack of information regarding its adsorption properties. Until we know, only an article evaluated the rate of adsorption of DDVP on soils. Kaur and Sud [18] reported the kinetic parameters of DDVP adsorbed onto Indian soils. They 
272 indicated that the adsorption followed a PSO mechanism whose rate constants ranging

273 from 6.5 to $15.77 \mathrm{~g} \mathrm{mg}^{-1} \mathrm{~h}^{-1}$. They attribute these differences to the heterogeneous nature

274 of soil particles and its variable composition [18]. These authors have used linearized

275 equations of PFO and PSO models so the results could have differences inherent to the

276 data processing.

277

$278 \quad 3.3$ Adsorption/desorption studies

279 The analysis of partition equilibrium is relevant to discuss the fate and transport of

280 compounds in soils. The isotherms represent the quantity of substance adsorbed onto soil

281 particles as a function of the equilibrium concentration in the bulk solution.

282 Sorption/desorption isotherms of the dichlorvos are presented in Figure 3 for the studied

283 soils where the adjustment to Langmuir and Freundlich models are indicated. Moreover,

284 Table 4 summarizes the adsorption parameters estimated in this work. 


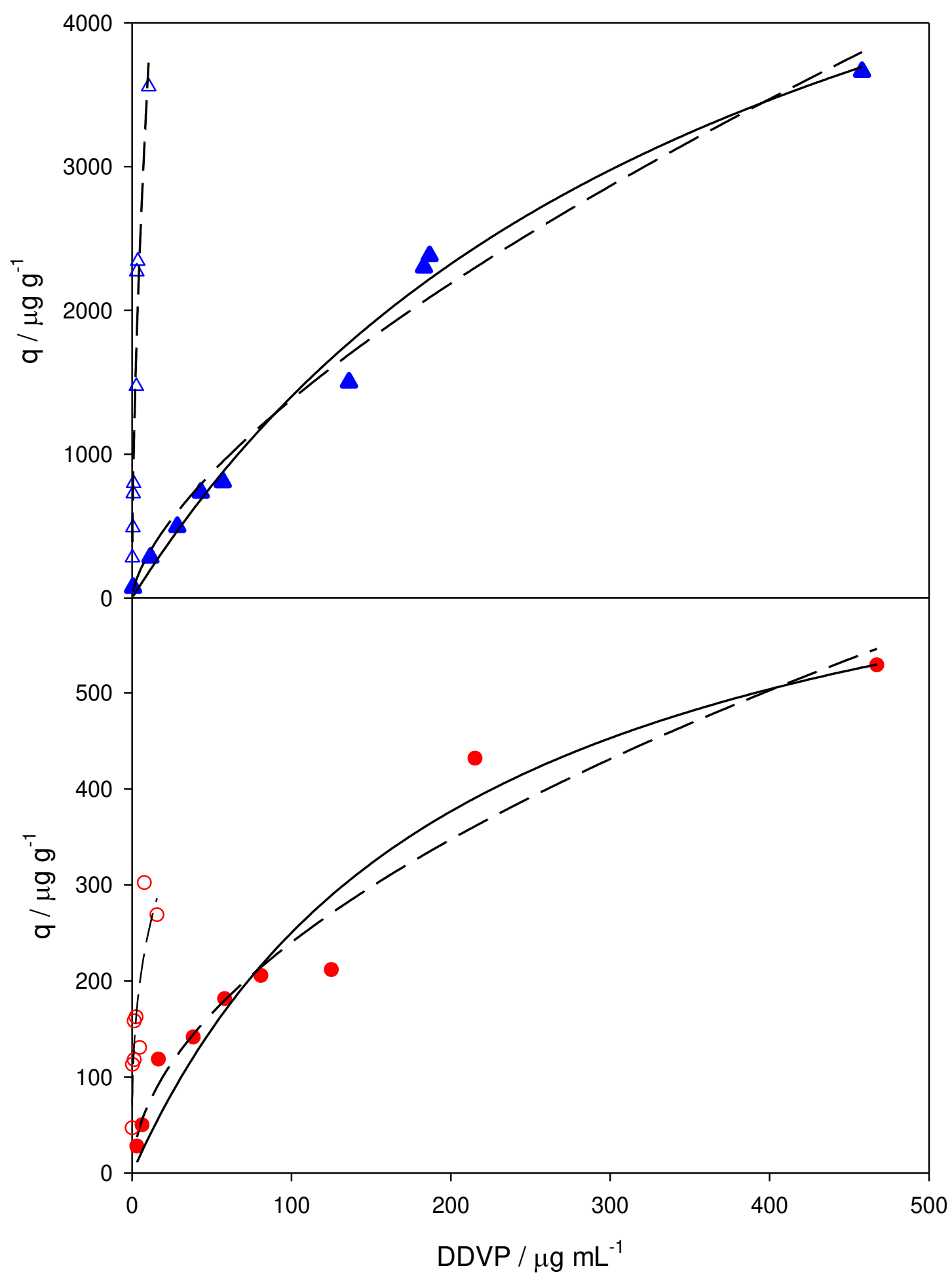

287 Figure 3. Relation between the mass of DDVP absorbed in soil versus concentration of 288 DDVP in the solution for MS ( $\boldsymbol{\Delta})$, and 9S (•). Fitting lines correspond to Langmuir (full 289 line), Freundlich (dashed line), and desorption studies (dotted line). Dots are experimental values (full) adsorption and (empty) desorption. 
291 Adsorption data have shown a good agreement with the Freundlich model within the

292

293

294

295

296

297

298

299

300

301

302

303

304

305

whole range of DDVP concentrations indicating that the adsorption sites were not fully occupied (any saturation is observed). Besides, $1 / \mathrm{n}$ values are lower than the unity in both soils, suggesting a diminution in the adsorption with increasing initial concentration. Moreover, there is not a linear relationship between the adsorbed and dissolved DDVP quantities. The constant values were $90 \mu \mathrm{g}^{(1-1 / \mathrm{n})} \mathrm{mL}^{(1 / \mathrm{n})} \mathrm{g}^{-1}$ and $21 \mu \mathrm{g}^{(1-1 / \mathrm{n})} \mathrm{mL}^{(1 / \mathrm{n})} \mathrm{g}^{-1}$ for MS and 9S, respectively. Differences could be attributed to the soil properties such as $\mathrm{pH}$, O.C., and clay fraction (Cox et al., 2000). Corrections regarding organic matter content can be done by dividing $K_{F}$ by the $\%$ of O.C of each soil. Thus, $K_{O C}$ values of $50 \mu \mathrm{g}^{(1-1 / \mathrm{n})}$ $\mathrm{mL}^{(1 / \mathrm{n})} \mathrm{g}^{-1}$ and $31 \mu \mathrm{g}^{(1-1 / \mathrm{n})} \mathrm{mL}^{(1 / \mathrm{n})} \mathrm{g}^{-1}$ were obtained were a lower variability between them is observed.

Table 3. Isotherm model parameters from adsorption and desorption for DDVP in soils MS and 9S.

\begin{tabular}{|c|c|c|c|c|}
\hline & Model & Parameter & MS & 9S \\
\hline \multirow{6}{*}{ 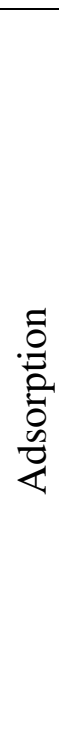 } & \multirow{3}{*}{ Langmuir } & $\mathrm{Q}_{0} / \mathrm{mg} \mathrm{g}^{-1}$ & $6.8 \pm 0.3$ & $006 \pm 0.05$ \\
\hline & & $\mathrm{K}_{\mathrm{L}} / \mathrm{L} \mathrm{mg}^{-1}$ & $\begin{array}{c}0.0043 \pm \\
0.0008\end{array}$ & $\begin{array}{c}0.005 \pm \\
0.002\end{array}$ \\
\hline & & $\mathrm{R}^{2}$ & 0.989 & 0.941 \\
\hline & \multirow{3}{*}{ Freundlich } & $1 / \mathrm{n}^{\mathrm{ads}}$ & $0.67 \pm 0.05$ & $0.53 \pm 0.03$ \\
\hline & & $\begin{array}{c}\mathrm{K}_{\mathrm{F}} \\
\mu \mathrm{g}^{(1-1 / \mathrm{n})} \mathrm{mL}^{(1 / \mathrm{n})} \mathrm{g}^{-1}\end{array}$ & $90 \pm 22$ & $21 \pm 5$ \\
\hline & & $\mathrm{R}^{2}$ & 0.984 & 0.969 \\
\hline
\end{tabular}




\begin{tabular}{|c|c|c|c|c|}
\hline \multirow{3}{*}{ 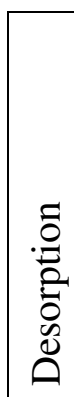 } & \multirow{3}{*}{ Freundlich } & $1 / \mathrm{n}^{\mathrm{des}}$ & $0.57 \pm 0.06$ & $0.31 \pm 0.07$ \\
\hline & & $\begin{array}{c}\mathrm{K}_{\mathrm{F}} \\
\mu \mathrm{g}^{(1-1 / \mathrm{n})} \mathrm{mL} \mathrm{L}^{(1 / \mathrm{n})} \mathrm{g}^{-1}\end{array}$ & $1304 \pm 120$ & $120 \pm 20$ \\
\hline & & $\mathrm{R}^{2}$ & 0.949 & 0.760 \\
\hline & $\mathrm{H}$ & & $0.9 \pm 0.1$ & $0.6 \pm 0.1$ \\
\hline
\end{tabular}

307 Desorption isotherms represent the quantity of DDPV that remains adsorbed per gram of soil after one desorption cycle as a function of the equilibrium concentration into the solution. In both cases, there was observed that the quantity of DDVP desorbed was lower than the total adsorbed. Thus, desorption coefficient values, $K_{D}$, were greater than the adsorption ones suggesting that the desorption process is unfavourable for DDVP on these soils (a high quantity of DDVP is retained after the desorption cycle). Hysteresis calculated from Eq. 10 is associated with the reversibility of the process, comparing indirectly the forces involved in both, the adsorption and the desorption [27]. In the present study, similar Freundlich desorption and adsorption coefficients were determined for MS (0.57 and 0.67, respectively) while for 9S, they were different $(0.31$ and 0.53 ) suggesting a non-reversible process. The hysteresis coefficient for these soils was close to $1(0.9)$ in MS, while 9S presented a positive hysteresis. As well, Barriuso et al. [23] reported a direct relationship between the adsorption constant and the hysteresis for atrazine adsorbed onto smectite. There, clay samples with low affinity by atrazine (low $\mathrm{K}_{\mathrm{ads}}$ ) exhibited positive hysteresis, and samples with high affinity showed negative hysteresis (passing for $\mathrm{H}=1$ ). These results are according to our findings where for $9 \mathrm{~S}$ the $\mathrm{K}_{\mathrm{F}}$ and the $\mathrm{H}$-values were minor than the obtained for MS (see table 3).

Taking into account only equilibrium data could be inferred that MS and 9S had different behaviour in connection with the DDVP movement. In fact, for the maxima concentration 
evaluated in this work, $500 \mu \mathrm{g} \mathrm{mL}^{-1}, 45 \%$ is adsorbed and the rest is lixiviated for MS.

327 Moreover, from the adsorbed quantity, only $2.66 \%$ is desorbed after the first desorption cycle. Otherwise, for 9S, at the same concentration, 93.6\% was lixiviated and the rest remains adsorbed. From this fraction, $50 \%$ is desorbed after the first cycle of desorption. Lixiviation implies a risk of leaching to groundwater sources while, in the opposite, the non-reversibility of the adsorption suggests a risk to surface waters by run-off. For evaluating the leaching associated risk, the groundwater ubiquitous score (GUS) values are normally used in the literature [28]. They are determined by the lifetime of pesticides and the adsorption constant in the soil; however, any consideration is done regarding equilibrium time and desorption constants or column results. For DDVP, a reported value of 0.69 indicates that this compound has a low lixiviation potential [12]. However, in the present article, it was demonstrated that the equilibrium time required is close to 24 hours to reach the maxima adsorption. This issue is not usually considered in the leaching index calculus; however, it could be underestimating the lixiviation risk for DDVP.

\subsection{Columns displacements assays}

342 The movement of pesticides through a soil column is due to convection, diffusion, and mechanic dispersion processes. The differential equation to describe the movement convective -dispersive of an adsorbed solute in a saturated soil under steady-state water flow conditions is as follow [29]:

where $\mathrm{t}$ is time, $\mathrm{x}$ is soil depth, $\mathrm{D}_{\mathrm{h}}$ is the hydrodynamic dispersion coefficient, $\mathrm{v}_{0}$ is the pore water velocity, $C$ is the solution concentration, and $\mathrm{R}(\mathrm{C})$ is the retardation factor. 
351 When the adsorption reactions are instantaneous, the equilibrium state relates the 352 solution-phase and adsorbed-phase concentrations trough the isotherm adsorption, and 353 then the retardation can be expressed as:

354

$R(C)=\left[1+\frac{\rho K(1 / n) C^{(1 / n)-1}}{\theta}\right]$

356

where $\rho$ is the soil bulk density and $\theta$ is the volumetric soil-water content.

For non-adsorbed solutes, the adsorption coefficient is equal to zero and $\mathrm{R}$ becomes one.

Otherwise, for adsorbed solutes, $\mathrm{R}(\mathrm{C})$ is greater that means: solute moves slower than the solvent front (retardation). Thus, larger values of $\mathrm{R}(\mathrm{C})$ indicate that the mobility is reduced along the soil column. Moreover, when the adsorbed and dissolved concentrations relationship is not linear, $(1 / \mathrm{n} \neq 1)$, this retardation is also a function of the initial concentration in the inlet flow.

However, if the adsorption does not take place instantly, a non-equilibrium condition is presented due to processes of chemical and physical nature (Rao et al., 1979). The first group considers that the limiting step rate is the reaction between the solute and the surface at the interphase. The second one implies that the adsorption takes place quickly, but the diffusion of the solution is the slow step. The degree of non-equilibrium is related to the adsorption kinetic rate constant, $\mathrm{k}$, and the residence time in the column, $\mathrm{t}_{\mathrm{r}}$ :

In our experiments, this value was around $0.035-0.03$ that is minor to the minimum value to assess equilibrium conditions into the column $(\omega \geq 5)$ [30]. In this context, it is 
expected that an eluted profile shows both effects, retardation (due to adsorption processes) and tailing at higher pore volumes (due to non-equilibrium adsorption conditions). Moreover, equilibrium conditions would be achieved under retention time greater than $71 \mathrm{~h}$, which means an equilibrium column volume around 140 times greater than column volumes used in our experiments. MS and 9J soil samples correspond to the 381 first soil layer (5-20 cm deep), so in field conditions, such equilibrium column volume will not be compouse by the same soil layer instead of deeper horizons with different soil properties.

In this work, breakthrough curves were obtained for tree DDVP concentrations $(1,5$, and $50 \mu \mathrm{g} \mathrm{ml}^{-1}$ ) using $\mathrm{MS}$ and 9S soil columns and maintaining constant the operation conditions (see Figure $4 \mathrm{~A}$ and B). The breakthrough curves were asymmetrical in shape suggesting that physical non-equilibrium processes were presented (in connection with the calculated non-equilibrium degree index).

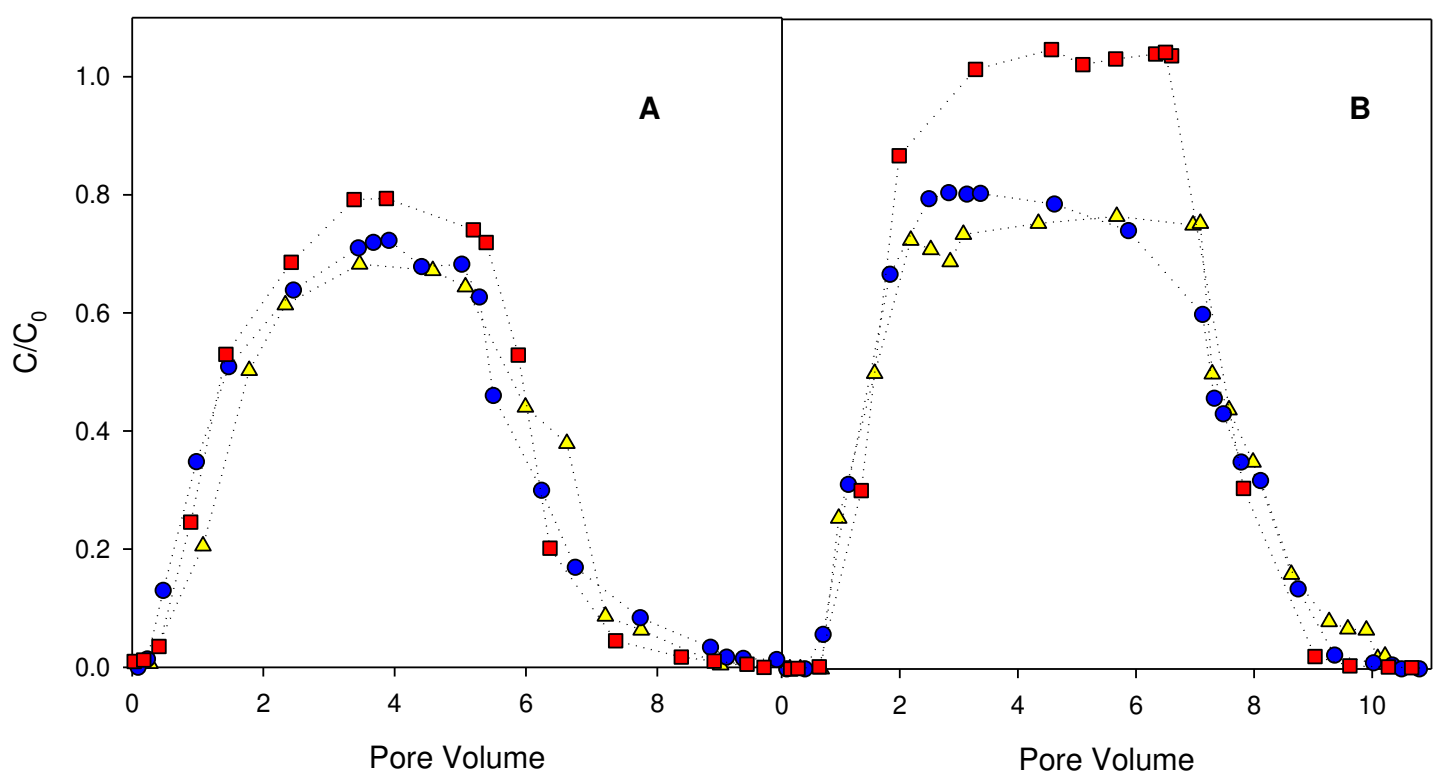

Figure 4. Breakthrough curves for DDVP at $\triangle 1 \mathrm{mg} \mathrm{L}^{-1} \bullet 5 \mathrm{mg} \mathrm{L}^{-1}$ and $₫ 50 \mathrm{mg} \mathrm{L}^{-1}$ for

A) Mercedes soil, B) 9 de Julio soil. 
Additionally, the pore volume needed to obtain the maximum value of $\mathrm{C} / \mathrm{C}_{0}$ was around 3.8 and 2.5 - 3.0 for Mercedes and 9 de Julio soils, respectively. This result suggests retardation in the DDVP movement [31]. Furthermore, the mobility in 9S soil is around 1.25 times higher than in MS that is according to the previous results presented in Table 3 were stronger adsorption is estimated for MS.

Moreover, from Figure 4A, it is observed a very short shift of BTC at $1 \mathrm{mg} \mathrm{L}^{-1}$ of DDVP. Despite that, for $\mathrm{C}_{0}$ of 5 and $50 \mu \mathrm{g} \mathrm{mL} \mathrm{m}^{-1}$, the retardation effect does not seem to be a function of the initial concentration. Similarly, for the sandy loam soil, 9S, no differences were found between the BTC curves at the tree DDVP concentrations. It is a surprising result considering the previous finding regarding batch experiments showing a non-linear adsorption isotherm $(1 / \mathrm{n}<1$ in both soils, see Table 3$)$. However, the short-range of studied concentrations could be also responsible. Both soils shown a tailing at large pore volumes, where the tailing observed for MS is around 1.6 more times bigger than the 9S one. Tailing effects were previously related to non-equilibrium adsorption processes and hysteresis effects [32]. The large time needed to reach the equilibrium condition (around 24 hours) makes that the time of residence is not enough to complete the adsorption processes due to kinetics aspects.

\section{Conclusions}

Adsorption assays of DDVP onto agricultural soils have great relevance to discuss the transport and environmental fate of plaguicides in agroecosystems. In this work, the studies were conducted on soils belonging to Buenos Aires province (Pampa Plain). Experimental adsorption data were adjusted satisfactorily to the Freundlich model being MS around five times more retentive than 9J at an equilibrium stage. Moreover, from desorption analysis, it was observed that the same tendency being MS eleven times more 
retentive than 9S after a desorption cycle. Even so, DDVP adsorption was characterized as a reversible process in MS but non-reversible in 9S. Regarding kinetic assays, it was indicated that both soils followed the kinetics of PSO whose constants were very similar. More important, it was also observed that the equilibrium state was achieved after 30 hours of the time of contact. In this context, column studies were necessary to explain the DDPV movement in agricultural soils. Breakthrough curves indicated that DDVP mobility is high in both soils being only 1.25 times faster in 9S. The eluted profile showed tailing effects associated with the hysteresis and non-linear adsorption isotherms as would be expected. This evidence suggests the importance of considering column studies to assess the fate of contaminants in environmental matrixes. Thus, predictions based only on the batch adsorption studies could underestimate the lixiviation processes.

In conclusion, DDVP had shown a high mobility trough soil columns as was predicted by the batch kinetics studies. This mobility was independent of the textural characteristics of the soils studied. From these results can be stated that the principal issue to assess DDVP mobility in soils is the kinetics analysis from batch and column experimental designs.

\section{$433 \quad$ Declarations}

Availability of data and materials

All data generated or analyzed during this study are available upon request.

\section{Competing interests}

437 The authors declare they have no competing interests.

\section{$438 \quad$ Funding}

439 This work was supported by Agencia Nacional de Promoción Científica y Tecnológica 440 (ANPCyT), Universidad de Buenos Aires (UBA), and Consejo Nacional de 441 Investigaciones Científicas y Técnicas (CONICET). 


\section{Authors' contributions}

444 NJ Bustos carry out the experiments, processed the information, and collaborated on the manuscript redaction; D. Grassi participated in the data discussion; A. Fernández Cirelli supplied the necessary materials and laboratory facilities to carry out the experiments. A.

447 Iriel was responsible for the experimental design, and the redaction of this manuscript. 448 All authors read and approved the final manuscript.

\section{Acknowledgements}

451 The authors gratefully acknowledge the financial support from Agencia Nacional de 452 Promoción Científica y Tecnológica (ANPCyT), Universidad de Buenos Aires (UBA), and Consejo Nacional de Investigaciones Científicas y Técnicas (CONICET).

\section{REFERENCES}

${ }^{1}$ Celik I, Suzek H. Effects of subacute exposure of dichlorvos at sublethal dosages on erythrocyte and tissue antioxidant defense systems and lipid peroxidation in rats. Ecotox Environ Saf. 2009; 72: $905-8$.

${ }^{2}$ Dunier M, Siwicki AK, Demaël A. Effects of organophosphorus insecticides: Effects of trichlorfon and dichlorvos on the immune response of carp (Cyprinus carpio): III. In Vitro effects on lymphocyte proliferation and phagocytosis and in Vivo effects on humoral response. Ecotox Environ Saf. 1991; 22: 79 - 87.

${ }^{3}$ Kim HH, Lim YW, Yang JY, Shin DC, Ham HS, Choi BS, et al. Health risk assessment of exposure to chlorpyrifos and dichlorvos in children at childcare facilities. Sci Total Environ. 2013; 444: 441 - 50 
${ }^{4}$ Hoang TC, Rand GM. Acute toxicity and risk assessment of permethrin, naled, and dichlorvos to larval butterflies via ingestion of contaminated foliage. Chemosphere, 2015; $120,714-21$.

${ }^{5}$ Okoroiwu HU, Iwara IA. Dichlorvos toxicity: A public health perspective. Interdiscip Toxicol, 2018; 11: 129 - 37. Accessed July 2019.

${ }^{6}$ Sattar MA. Fate of organophosphorus pesticides in soils. Chemosphere. 1990; 20: 387 - 96.

${ }^{7}$ Khan SU. Pesticides in the soil environment. Elsevier. Netherlands. 2016.

${ }^{8}$ Bustos N, Cruz-Alcalde A, Iriel, A, Cirelli, AF, Sans, C. Sunlight and UVC-254 irradiation induced photodegradation of organophosphorus pesticide dichlorvos in aqueous matrices. Sci Total Environ. 2019; 649: 592 - 600.

9 Australian Pesticides \& Veterinary Medicines Authority (APVMA). Dichlorvos, Environmental Assessment: The reconsideration of approvals of the active constituent, registrations of products containing dichlorvos and approvals of their associated labels. 2008. https://apvma.gov.au/node/15066. Accessed July 2019.

${ }^{10}$ Lamoreaux RJ, Newland LW. The fate of dichlorvos in soil. Chemosphere. 1978; 7: $807-14$.

${ }^{11}$ Carriquiriborde P, Díaz J, Mugni H, Bonetto C, Ronco AE. Impact of cypermethrin on stream fish populations under field-use in biotech-soybean production. Chemosphere. 2007; 68: $613-21$.

${ }^{12}$ Sánchez-Bayo F, Tennekes HA. Environmental risk assessment of agrochemicals-A critical appraisal of current approaches. In: Larramendy ML, Soloneski S. Eds. Toxicity and Hazard of Agrochemicals. Intech Open; 2015. p. 1 - 38. 
${ }^{13}$ Directive 2013/39/EU of the European Parliament and of the Council of 12 August 2013 amending Directives 2000/60/EC and 2008/105/EC as regards priority substances in the field of water policy Off J Eur Union. 2013; L226: 1-17.

${ }^{14}$ Nasrabadi T, Bidhendi GN, Karbassi A, Grathwohl P, Mehrdadi N. Impact of major organophosphate pesticides used in agriculture to surface water and sediment quality (Southern Caspian Sea basin, Haraz River). Environ Earth Sci. 2011; 63: 873 - 83.

${ }^{15}$ Tanik A, Gurel M, Zeren O, Gonenc IE, Arslan H, Uysal Y, et al. Fate of pesticides in soil in a coastal lagoon area and associated water quality impacts. Water Sci. Technol., 2002; 45: $111-20$.

${ }^{16}$ Brodeur JC, Sanchez M, Castro L, Rojas DE, Cristos D, Damonte MJ, et al. Accumulation of current-use pesticides, cholinesterase inhibition and reduce body condition in juvenile one-sided livebearer fish (Jenynsia multidentata) from the agricultural Pampa region of Argentina. Chemosphere. 2017; 185: 36 - 46.

${ }^{17}$ D'Andrea, MF, Létourneau G, Rousseau AN, Brodeur JC. Sensitivity analysis of the Pesticide in Water Calculator model for applications in the Pampa region of Argentina. Sci Total Environ. 2020; 698: 134232.

${ }^{18}$ Kaur P, Sud D. Adsorption kinetics, isotherms, and desorption of monocrotophos and dichlorvos on various Indian soils. Clean-Soil, Air, Water. 2011; 39: 1060 - 7.

${ }^{19}$ Jones Jr JB. Laboratory guide for conducting soil tests and plant analysis. CRC press; 2001.

${ }^{20}$ OECD Guidelines for the Testing of Chemicals, Section 1. Physical-Chemical Properties. O.E.C.D. 106: Adsorption-Desorption Using a Batch Equilibrium Method, 2000.

${ }^{21}$ Bhattacharya AK, Venkobachar C. Removal of cadmium (II) by low cost adsorbents. J Environ Eng. 1984; 110: 110 - 22. 
${ }^{22}$ Ho YS, McKay G. Pseudo-second order model for sorption processes. Process Biochem. 1999; 34: $451-65$.

${ }^{23}$ Barriuso E, Laird DA, Koskinen WC, Dowdy RH. Atrazine desorption from smectites. Soil Sci Soc Am J. 1994; 58: 1632 - 8.

${ }^{24}$ Di Rienzo JA, Casanoves F, Balzarini MG, Gonzalez L, Tablada, M, Robledo YC. InfoStat versión 2011. Grupo InfoStat, FCA, Universidad Nacional de Córdoba, Argentina. URL http://www. infostat.com.ar, 2011; 8: 195 - 9.

${ }^{25}$ Cox L, Celis R, Hermosin MC, Cornejo J, Zsolnay A, Zeller K. Effect of organic amendments on herbicide sorption as related to the nature of the dissolved organic matter. Environ Sci Technol. 2000; 34: 4600 - 5.

${ }^{26}$ Ho YS, McKay G. Sorption of dyes and copper ions onto biosorbents. Process Biochem. 2003; 38: 1047 - 61.

${ }^{27}$ Sukul P, Lamshöft M, Zühlke S, Spiteller M. Sorption and desorption of sulfadiazine in soil and soil-manure systems. Chemosphere. 2008; 73:1344 - 50.

${ }^{28}$ Gustafson D.I. Groundwater ubiquity score: a simple method for assessing pesticide leachability. Environ Toxicol Chem 1989; 8: 339 - 57.

${ }^{29}$ Rao PSC, Davidson JM, Jessup RE, Selim HM. Evaluation of conceptual models for describing nonequilibrium adsorption-desorption of pesticides during steady-flow in soils. Soil Sci Soc Am J. 1979; 43: 22 - 8.

${ }^{30}$ Rao PSC, Jessup RE. Sorption and movement of pesticides and other toxic organic substances in soils. In: Nelson DW, Elrick DE, Tanji KK, editors. Chemical mobility and reactivity in soil systems. Wiley; 1983. P. 183-201.

${ }^{31}$ Van Genuchten MT, Cleary RW. Movement of solutes in soil: Computer-simulated and laboratory results. In: Bolt GH, editor. Developments in soil science. Elsevier; 1979. p. 349 - 86. 
32 Van Genuchten, MT, Davidson JM, Wierenga PJ. An evaluation of kinetic and equilibrium equations for the prediction of pesticide movement through porous media. Soil Sci Soc Am J. 1974; 38: 29 - 35. 
Figures

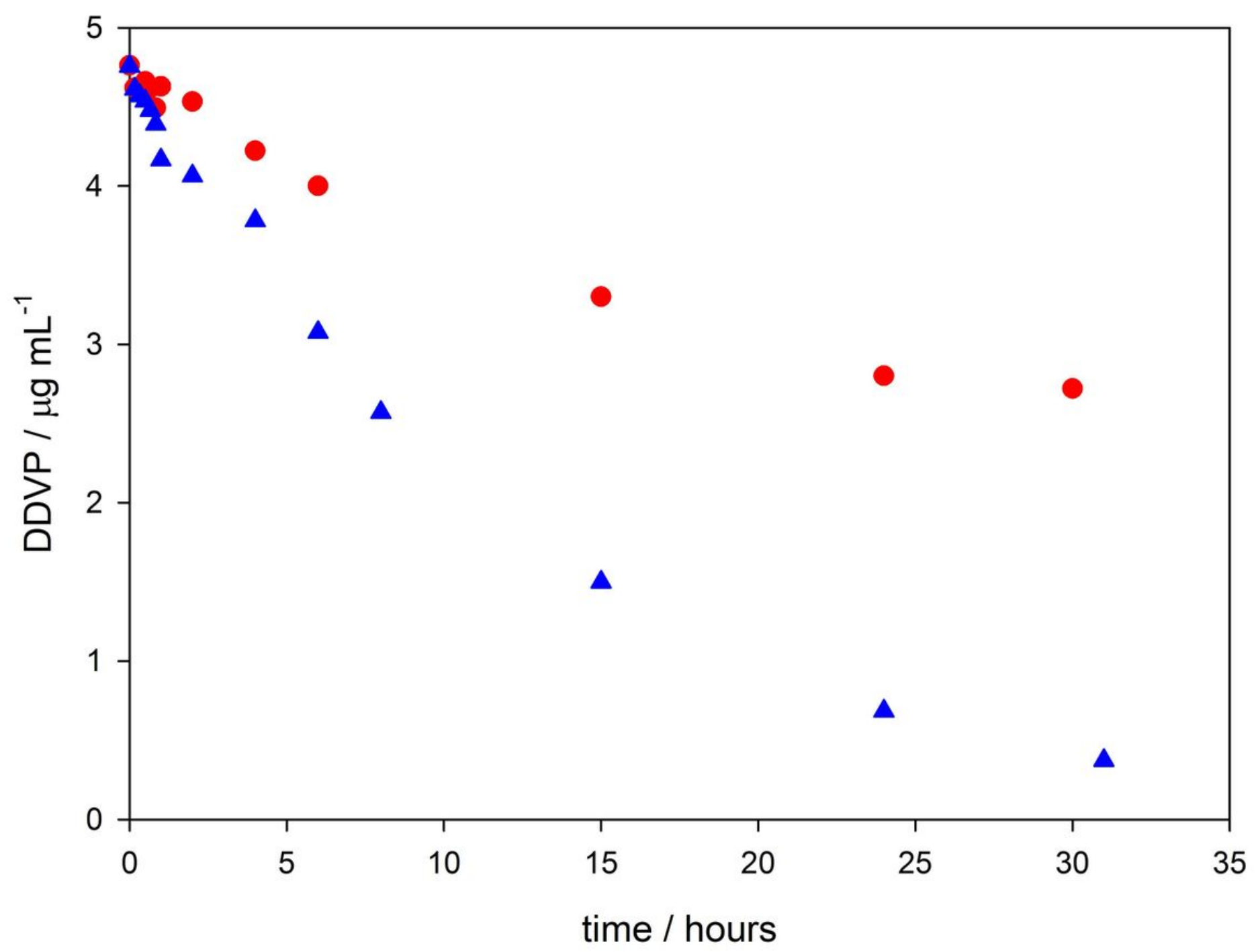

Figure 1

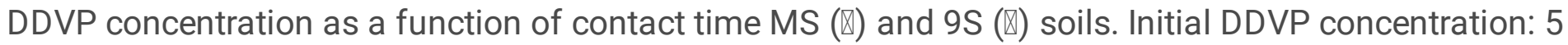
$\mu \mathrm{g} \mathrm{mL}-1$, soil dosage: $6 \mathrm{~g} \mathrm{~L}-1$. 


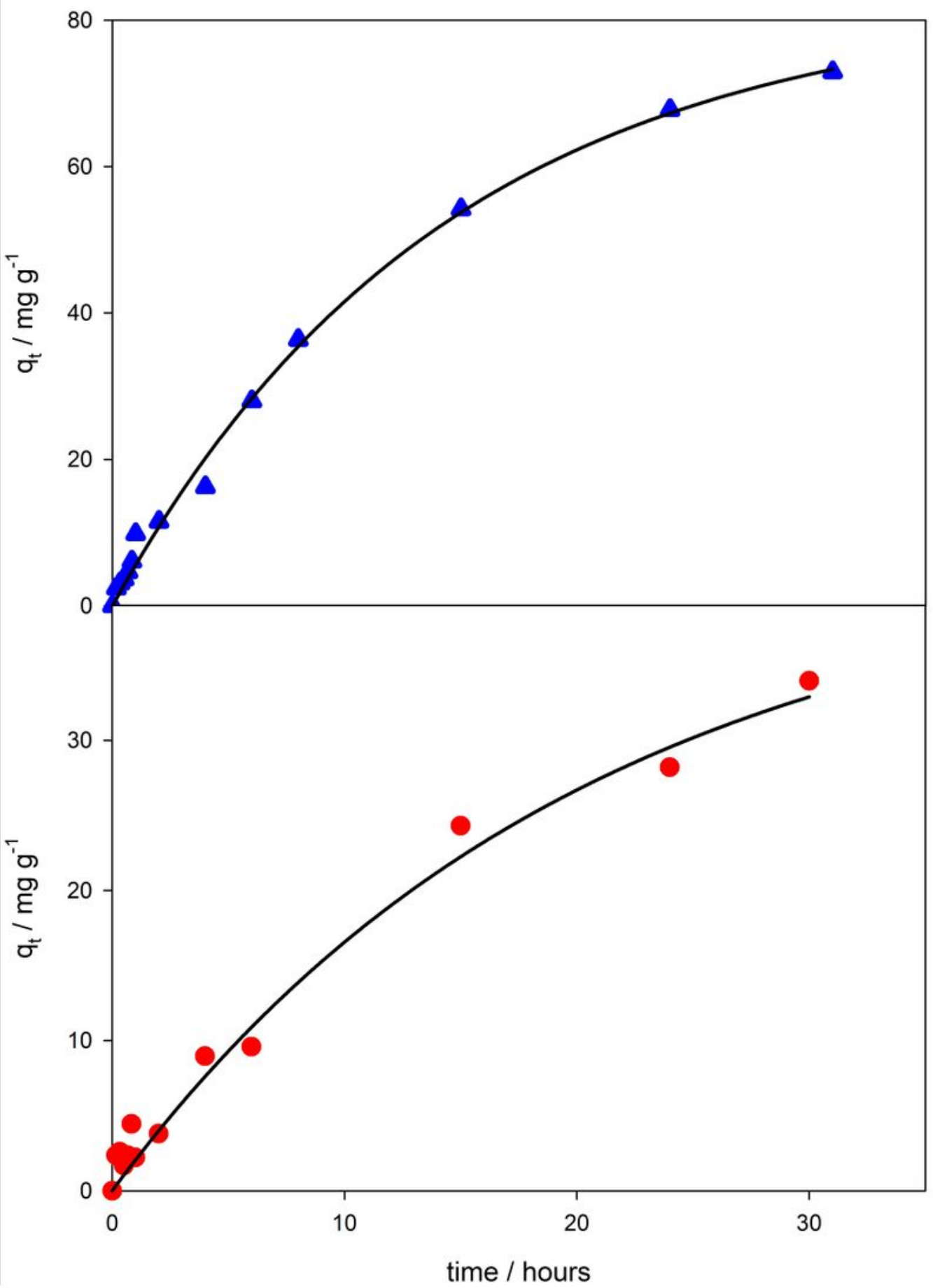

\section{Figure 2}

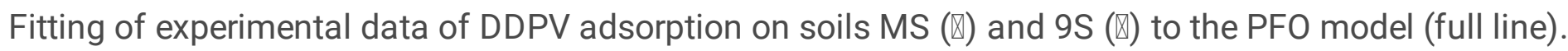




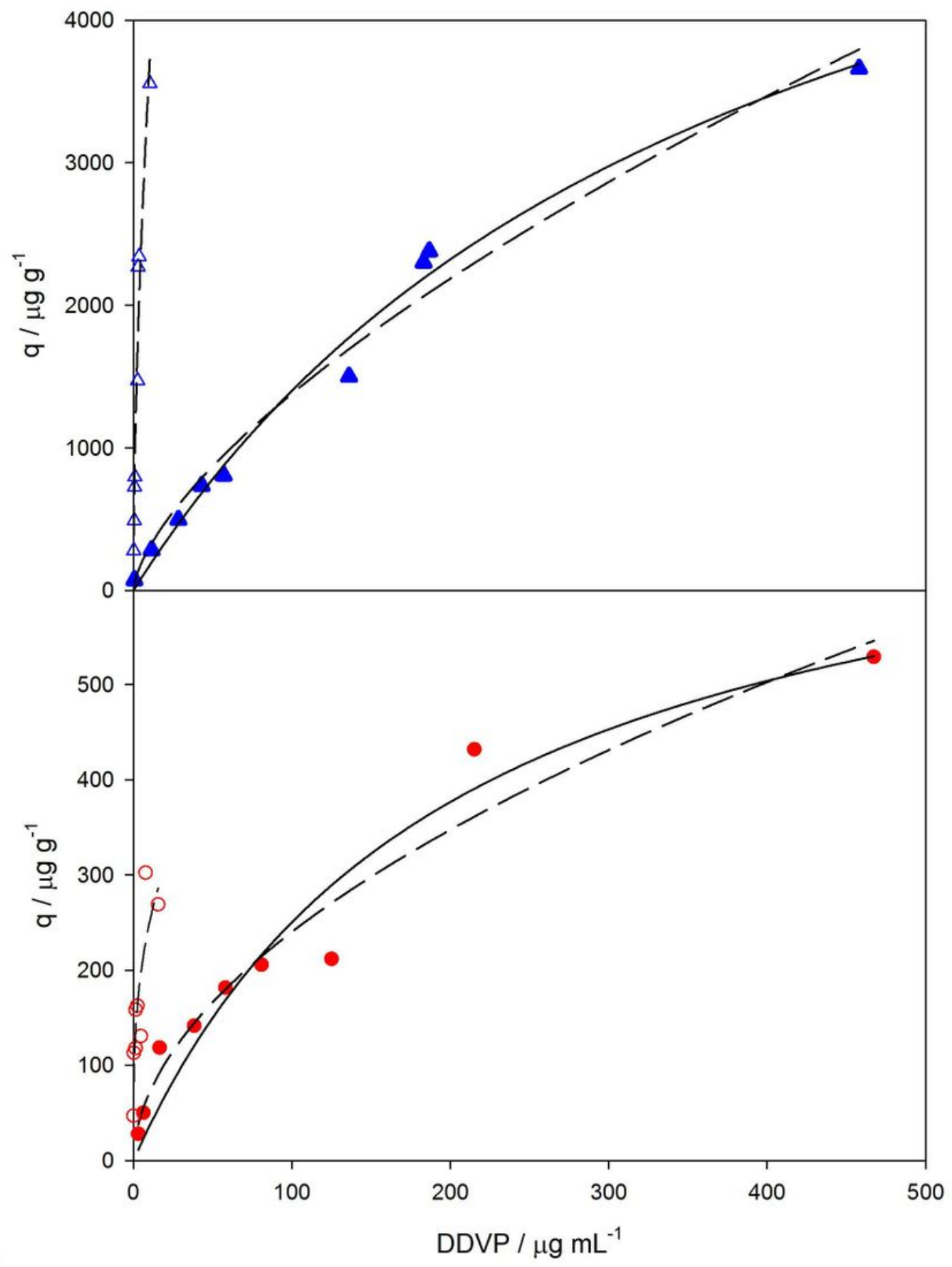

\section{Figure 3}

Relation between the mass of DDVP absorbed in soil versus concentration of DDVP in the solution for MS ( $)$, and 9S ( () . Fitting lines correspond to Langmuir (full line), Freundlich (dashed line), and desorption studies (dotted line). Dots are experimental values (full) adsorption and (empty) desorption. 


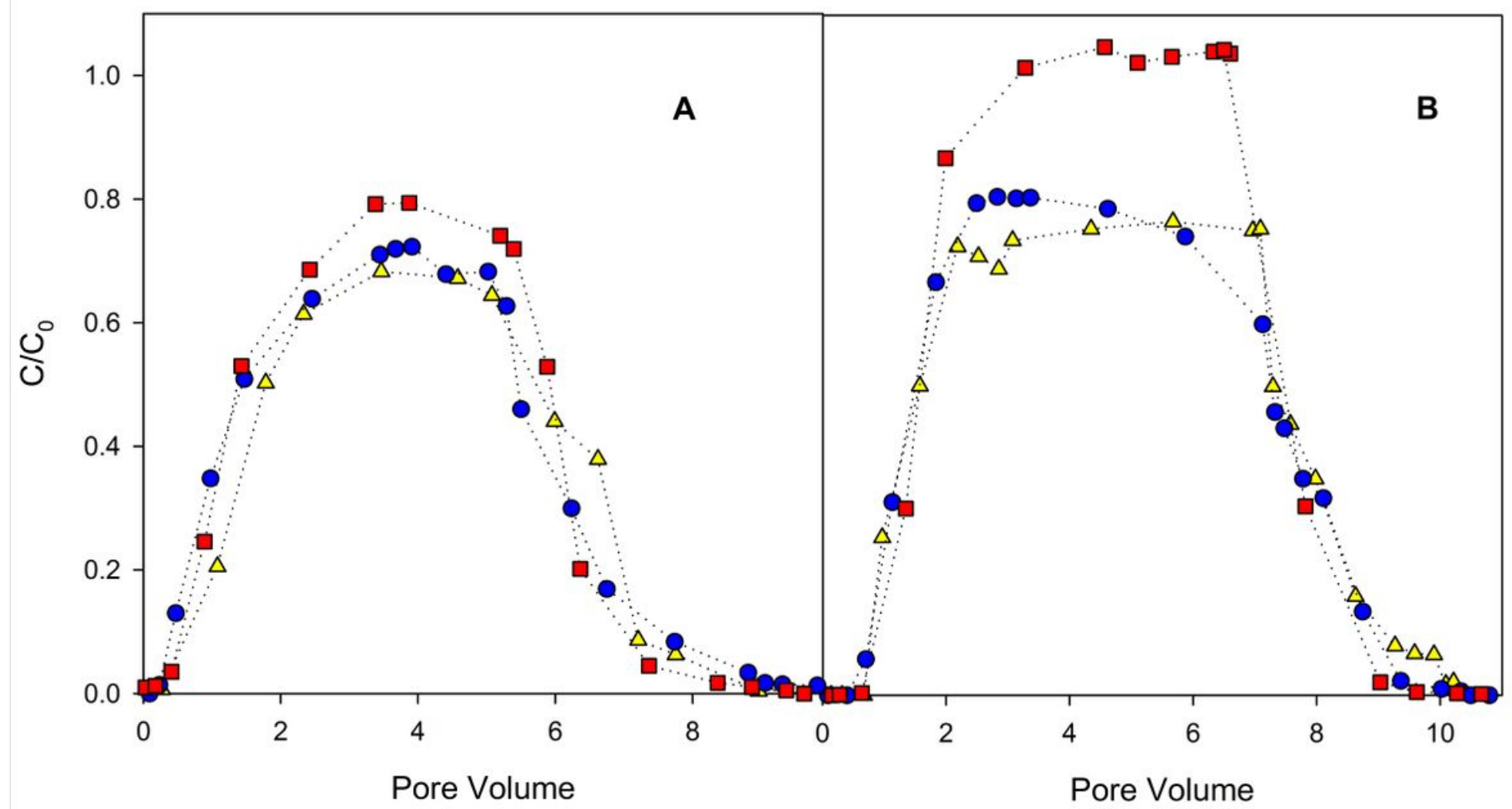

Figure 4

Breakthrough curves for DDVP at $\otimes 1 \mathrm{mg} \mathrm{L}-1 \otimes 5 \mathrm{mg} \mathrm{L}-1$ and $\otimes 50 \mathrm{mg} \mathrm{L}-1$ for A) Mercedes soil, B) 9 de Julio soil. 